\title{
Kadsurenone is a useful and promising treatment strategy for breast cancer bone metastases by blocking the PAF/PTAFR signaling pathway
}

\author{
TIANHUI HOU ${ }^{1,2 *}$, YAN LOU ${ }^{2 *}$, SHICHANG LI ${ }^{1 *}$, CHENGLONG ZHAO $^{2}$, YINGZHENG JI $^{2}$, \\ DONGSHENG WANG ${ }^{2}$, LIANG TANG ${ }^{2}$, MING ZHOU ${ }^{1}$, WEI XU ${ }^{2}$, MING QIAN $^{2}$, \\ ZHIPENG WU ${ }^{2}$, JIAN ZHAO ${ }^{2}$, HAIFENG WEI ${ }^{2},{\text { ZHENXI } \text { LI }^{2} \text { and JIANRU XIAO }}^{2}$ \\ ${ }^{1}$ Key Laboratory of Adolescent Health Assessment and Exercise Intervention, Ministry of Education, \\ School of Physical Education and Health Care, East China Normal University, Shanghai 200241; \\ ${ }^{2}$ Spine Tumor Center, Department of Orthopedic Oncology, Changzheng Hospital, \\ Second Military Medical University, Shanghai 200003, P.R. China
}

Received July 27, 2017; Accepted May 31, 2018

DOI: $10.3892 / \mathrm{ol} .2018 .8935$

\begin{abstract}
Breast cancer (BC) is characterized by high incidences of bone metastases. Current treatment strategies for $\mathrm{BC}$ bone metastases primarily focused on breaking the 'vicious osteolytic cycle'. Platelet-activating factor (PAF) is a potent phospholipid mediator, which has previously reported biological activities in BC progression and osteoclast differentiation by activating its receptor PAF receptor (PTAFR). However, the role of PAF in the mediation of BC bone metastases remains elusive. In the present study, it was revealed that the upregulation of PTAFR was associated with an increased incidence of bone metastases. It was also revealed that PAF significantly enhanced the processes of BC cell migration and $\mathrm{BC}$ mediated osteoclastogenesis. These
\end{abstract}

Correspondence to: Dr Jianru Xiao or Dr Zhenxi Li, Spine Tumor Center, Department of Orthopedic Oncology, Changzheng Hospital, Second Military Medical University, 415 Fengyang Road, Shanghai 200003, P.R. China

E-mail: xiaojianruvip@163.com

E-mail: zhenxili.ecnu@gmail.com

${ }^{*}$ Contributed equally

Abbreviations: $\mathrm{BC}$, breast cancer; $\mathrm{PAF}$, platelet-activating factor; PTAFR, platelet-activating factor receptor; OG, osteoclatogenic; $\mathrm{NF}-\kappa \mathrm{B}$, nuclear factor- $\kappa \mathrm{B} ; \mathrm{P} / \mathrm{S}$, penicillin-streptomycin; BMMs, bone marrow monocytes; $\alpha$-MEM, $\alpha$-minimum essential medium; Trap, tartrate-resistant acid phosphatase; RANKL, receptor activator for NF- $\kappa \mathrm{B}$ ligand; GPCR, G-protein coupled receptor; IL, interleukin; MMP, matrix metalloproteinase; PTHRP, parathyroid hormone like hormone; TNF $\alpha$, tumor necrosis factor- $\alpha$; OPG, osteoprotegerin; OPN, osteopontin; TGF $\beta$, transforming growth factor- $\beta$; BMP, bone morphogenetic protein; IGF, insulin-like growth factor

Key words: breast cancer, bone metastases, PAF, Kadsurenone, vicious osteolytic cycle, osteoclastogenesis results suggest that PAF serves a promotion role in $\mathrm{BC}$ bone metastases. It was further demonstrated that the natural PAF antagonist Kadsurenone may effectively attenuate each process by partially blocking the PAF/PTAFR signaling pathway. Therefore, targeting PAF/PTAFR by Kadsurenone may be a promising treatment strategy for BC bone metastases.

\section{Introduction}

Breast cancer (BC) is the most common malignant tumor in women patients $(1,2)$. $\mathrm{BC}$ is responsible for the majority of skeletal metastases, and the incidence of bone metastases is $65-75 \%$ in advanced diseases (3). Bone metastases are a major cause for morbidity, the median survival of $\mathrm{BC}$ patients with bone metastases is 19-25 months (4). Bone metastases are characterized by severe pain, impaired mobility, pathologic fractures, spinal cord compression, bone marrow aplasia and hypercalcemia $(5,6)$. Metastatic cancer cells could secrete a series of factors into the bone-tumor microenvironment and form an osteolytic lesion, and bone matrix released growth factors could reversely stimulate BC cell proliferation. The interactions of $\mathrm{BC}$ cells and bone formed a 'vicious osteolytic cycle' $(7,8)$. With the advantages of modern science, treatment strategies for primary breast tumors are well developed, while clinical interventions for bone lesions are still unsatisfying $(9,10)$. Therefore, finding targets which could prevent or cure bone metastases is a priority for cancer treatment.

Platelet-activating factor (PAF, 1-O-alkyl-2-acetylsnglycero-3-phosphocholine), a potent phospholipid mediator, has been shown to play a role in a number of biological pathways including inflammatory diseases, cardiovascular homeostasis as well as in cancer, by binding to the G-protein coupled receptor (GPCR) PAF receptor (PTAFR) (11). PAF play important roles in platelet aggregation, stimulation of neutrophils and macrophages, inflammation and allergic responses $(12,13)$. It also play vital roles in tumor neo-angiogenesis by activation of nuclear factor- $\kappa \mathrm{B}(\mathrm{NF}-\kappa \mathrm{B})(14,15)$. PAF has been reported highly expressed in BC cells but not in normal MECs. The 
Kaplan-Meier analysis showed that high levels of PAF expression were strongly associated with poor prognosis in BC (16) Bussolati et al reported that BC cell lines MDA-MB-231 and MCF-7 could secret PAF and increase the motility of cancer cells by an autocrine manner (17). The upregulation of PTAFR has also been observed in several BC cell lines. Recently, Anandi et al reported that PAF could promote motility in BC cells and distupts non-transformed breast acinar structures (18). All these findings highlighted the potential role of PAF/PTAFR signaling pathway in $\mathrm{BC}$ progression.

The bone microenvironment is a highly dynamic system balanced between osteoclastic breakdown and osteoblastic rebuilding under tightly control in a local, coordinated, and sequential manner (19). Interruption of the homeostasis of bone microenvironment by tumor cells is one of the most important mechanisms of $\mathrm{BC}$ bone metastases. In vitro studies has demonstrated that PAF could directly enhance osteoclast motility and resorptive activity $(20,21)$. Clinical studies also indicates that higher plasma PAF levels are associated with increased risk of vertebral fracture and lower bone mineral density in postmenopausal women (22). Hence, blocking PAF induced osteoclastogenesis might be an effective strategy in treatment of osteoclast related diseases, including osteolytic $\mathrm{BC}$ bone metastases.

Kadsurenone is a natural product isolated from stems of Piper kadsura. This herb is used in traditional Chinese medicine for the relief of diseases as asthma and rheumatoid arthritis (RA) (23). Kadsurenone have been demonstrated as a natural PAF inhibitor which could stops or diminishes all unwanted reactions induced by PAF (24). In the current study, we revealed that the upregulation of PTAFR is associated with increased incidence of bone metastases. We also demonstrated that Kadsurenone could effectively inhibit PAF induced BC cell migration. Furthermore, Kadsurenone could also attenuate BC induced osteolytic bone metastases by blocking the PAF/PTAFR signaling pathway.

\section{Materials and methods}

Bioinformatics analysis. The online Oncomine database (www.oncomine.org) were used to reveal PTAFR expression patterns between normal breast tissues and invasive breast carcinomas. Involved expression data were deposited in the National Center for Biotechnology Information/Gene Expression Omnibus database entries GSE9014. Data for survival analysis of bone metastasis and PTAFR expression patterns between osteoclatogenic (OG) and non-OG cell lines were obtained from GSE2603 and GSE43811, respectively. Survival analyses were based on Kaplan-Meier method, cutoff value was determined by ROC curves.

Cells and culture conditions. MDA-MB-231, RAW 264.7 and 293 T cells were all obtained from the Type Culture Collection of the Chinese Academy of Sciences (Shanghai, China). MDA-MB-231 and 293T cells were cultured in Dulbecco's modified Eagle's medium (DMEM; Gibco; Thermo Fisher Scientific, Inc., Waltham, MA, USA), supplied with $10 \%$ fetal bovine serum (FBS; HyClone; GE Healthcare Life Sciences, Logan, UT, USA) and $100 \mathrm{U} / \mathrm{ml}$ penicillin-streptomycin (P/S; Gibco; Thermo Fisher Scientific, Inc.). RAW264.7 cells and mouse bone marrow monocytes (BMMs) were cultured in $\alpha$-minimum essential medium ( $\alpha$-MEM; Gibco; Thermo Fisher Scientific, Inc.), supplied with $10 \%$ FBS and $100 \mathrm{U} / \mathrm{ml}$ $\mathrm{P} / \mathrm{S}$. Cells were cultured in a humidified incubator (Thermo Fisher Scientific, Inc.) with $5 \% \mathrm{CO}_{2}$ at $37^{\circ} \mathrm{C}$.

Cell viability assay. The viability and cytotoxicity effect of Kadsurenone was determined by the MTS method following the manual of CellTiter 96 Aqueous One Solution Cell Proliferation assay (Promega Corporation, Madison, WI, USA) with VERSA max microplate reader (Molecular Devices, LLC, Sunnyvale, CA, USA) as described previously.

Transwell asssy. The transwell assay were performed with Boyden chambers (Corning Incorporated, Corning, NY, USA). MDA-MB-231 cells were collected and resuspend in blank DMEM after 12 -h serum starve. $6 \times 10^{5}$ cells were plated in the top chambers with or without $200 \mathrm{nM}$ PAF and different concentrations $(0,0.5,1,2.5$ and $5 \mu \mathrm{M})$ of Kadsurenone. The bottom chambers were filled with $600 \mu 1$ mediums supplemented with $2 \%$ FBS. After $8 \mathrm{~h}$ incubation, migrated cells were fixed with $4 \%$ paraformaldehyde (PFA) and stained with $1 \%$ crystal violet. Images were taken using an Olympus inverted microscope (Olympus Corporation, Tokyo, Japan) and migrated cells were counted using Image-Pro Plus 6.0 (Media Cybernetics, Inc., Rockville, MD, USA).

Luciferase reporter gene assay. Dual luciferase assays were conducted in a 24-well plate format. Vectors were transfected into $70 \%$ confluent HEK293 cells, PAF or receptor activator for NF- $\kappa \mathrm{B}$ ligand (RANKL) inducement and different concentrations of Kadsurenone were added. After 48-h transfection, frefly and renilla luciferase were quantified sequentially using the Dual Luciferase Assay kit (Promega Corporation) following the manufacturer's recommendations.

$B C$ cells induced osteoclast differentiation assay. $2 \times 10^{3}$ MDA-MB-231 cells and 5X103 RAW264.7 cells were pooled together and seeded into 24-well plates. Cells were cultured in $\alpha$-MEM added with $10 \%$ FBS and different concentrations of Kadsurenone. After 5-7 days, cells were fixed with 4\% PFA and permeabilized with $0.1 \%$ Triton-X 100 inPBS for $5 \mathrm{~min}$, and subjected to tartrate-resistant acid phosphatase (Trap) staining with Leukocyte acid phosphatase kit (Sigma-Aldrich; Merck KGaA, Darmstadt, Germany). Trap positive osteoclasts were photographed and counted thereafter.

Mouse BMMs isolation and osteoclast differentiation assay. Mouse BMMs were flushed and isolated from C57/BL6 mice as previously described. $8 \times 10^{3} \mathrm{BMMs}$ were seeded into 96-well plates and incubated with $10 \mathrm{ng} / \mathrm{ml} \mathrm{M-CSF}, 50 \mathrm{ng} / \mathrm{ml}$ RANKL and different concentrations of Kadsurenone. After 5-7 days, cells were fixed and subjected to Trap staining and photographed. All experimental protocols were approved by the Review Committee for the Use of Human or Animal Subjects of East China Normal University and Chang Zheng Hospital (Shanghai, China).

Acting ring formation assay. Mouse BMMs were isolation and induced for osteoclast differentiation for 5-7 days. Cells were 
then permeabilized with Triton X-100 and incubated with rhodamine conjugated phalloidin (Molecular Probes; Thermo Fisher Scientific, Inc.) to visualize F-actin.

RNA extraction and gene expression analysis. Mouse BMMs were isolated and induced for osteoclast differentiation with or without indicated concentrations of Kadsurenone. Cells were collected and total RNA were extracted with TRIzol reagent (Invitrogen; Thermo Fisher Scientific, Inc.). Then, 500 ng total RNA were reverse transcribed with PrimeScript ${ }^{\mathrm{TM}}$ RT Master Mix (Takara Biotechnology Co., Ltd., Dalian, China), according to the manufacturer's instructions. The complementary DNA was used for reverse transcription-quantitative polymerase chain reaction (RT-qPCR) and a final volume of $20 \mu \mathrm{l}$ was adopted as follows: $10 \mu 1$ XX SYBR Premix Ex Taq (Takara Biotechnology Co., Ltd.), $1 \mu \mathrm{l}$ forward and reverse primers, $2.5 \mu \mathrm{M}, 2 \mu \mathrm{l}$ cDNA, $7 \mu \mathrm{lddH_{2 }}$ O. PCR and data collection were performed on Mx3000P QPCR system (Stratagene; Agilent Technologies, Inc., Santa Clara, CA, USA) and data analysis was operated with the $2^{-\Delta \Delta \mathrm{Cq}}$ method normalized to the endogenous control $\beta$-actin. Primers used in RT-qPCR are listed in Table I.

Statistical analysis. Experiments were performed with 3 or more replicates. The results were reported as the mean \pm standard error of the mean. The differences between control and experimental groups were determined using an unpaired Student's t-test or one-way analysis of variance followed by Tukey's post hoc test. Survival curves were analyzed by log-rank test. $\mathrm{P}<0.05$ was considered to indicate a statistically significant difference.

\section{Results}

Bioinformatics analysis of PTAFR expression in BC tissues and osteoclastogenic $(O G)$ cell lines. Using the Oncomine database (www.oncomine.org), we compared the expression patterns of PTAFR between normal breast tissues and invasive breast carcinomas PTAFR was significantly upregulated in cancer patients with a fold change of 3.88 ( $\mathrm{P}<0.001$; Fig. 1A). We further examined prognostic value of PTAFR expression level in BC bone metastasis by Minn's dataset (25). Although no significance was drown $(\mathrm{P}=0.0992, \mathrm{P}<0.1), \mathrm{BC}$ with higher expression levels of PTAFR $(n=19)$ still indicated a tendency for bone metastases (Fig. 1B). We also revealed the expression patterns of PTAFR between OG and non-OG cell lines in GSE43811. PTAFR was significantly upregulated after RANKL stimulation in OG Raw264.7 cells (Fig. 1C).

Kadsurenone inhibits PAF induced BC cell migration. Kadsurenone is a natural product isolated from stems of Piper kadsura. Chemical structure of Kadsurenone was shown in Fig. 2A. We first tested cytotoxicity of Kadsurenone on BC cell line MDA-MB-231. No significant disturb of cell viability was observed with a highest concentration of $5 \mu \mathrm{M}$ (Fig. 2B).

We then examined effects of Kadsurenone on PAF induced MDA-MB-231 cells migration. Transwell assay shown that Kadsurenone could dose dependently inhibit PAF induced BC cells migration (Fig. 2C and D). Luciferase assay indicated that the NF- $\kappa$ B activity of MDA-MB-231 cells were significantly inhibited by Kadsurenone dose dependently (Fig. 2E). Our
Table I. Primer sequences for reverse transcription-quantitative polymerase chain reaction.

\begin{tabular}{lll}
\hline Gene & Direction & \multicolumn{1}{c}{ Sequence } \\
\hline$\beta$-actin & Forward & 5'-GTACGCCAACACAGTGCTG-3' \\
& Reverse & 5'-CGTCATACTCCTGCTTGCTG-3' \\
Ctsk & Forward & 5'-CTTCCAATACGTGCAGCAGA-3' \\
& Reverse & 5'-TCGGTTTCTTCTCCTCTGGA-3' \\
Trap & Forward & 5'-GCTGGAAACCATGATCACCT-3' \\
& Reverse & 5'-GAGTTGCCACACAGCATCAC-3' \\
Nfatc1 & Forward & 5'-TGGAGAAGCAGAGCACAGAC-3' \\
& Reverse & 5'-GCGGAAAGGTGGTATCTCAA-3' \\
& & \\
\hline
\end{tabular}

Trap, tartrate-resistant acid phosphatase; Ctsk, cathepsin K; Nfatc1, nuclear factor of activated T cells 1 .

data proved that Kadsurenone did not disturb the cell viability significantly but suppressed cell migration in MDA-MB-231 cells, which indicated that PAF/PTAFR played key role in cell migration but not cell viability.

Kadsurenone inhibits BC cells induced osteoclastogenesis. In the bone microenvironment, BC cells could stimulate osteoclast differentiation directly through excretion of cytokines such as interleukin (IL)-1 $\beta$, tumor necrosis factor- $\alpha$ (TNF $\alpha$ ). $\mathrm{BC}$ cells could also indirectly promote osteoclast differentiation via upregulation of RANKL by osteoblast. Therefore, we intended to study whether Kadsurenone could directly inhibit BCs induced osteoclastogenesis. MDA-MB-231 cells, which could secret PAF, were co-cultured with the OG cell line RAW264.7 cells. We proposed to use this co-culture system mimic the BC bone metastases microenvironment. BC cells could induce RAW264.7 cells differentiate into Trap positive osteoclasts. However, this process could be attenuated by Kadsurenone dose dependently (Fig. 3).

Kadsurenone directly inhibits RANKL induced osteoclastogenesis. It is reported that BMMs could secret PAF as an autocrine factor and promote the OG process (26). Therefore, we intend to investigate whether Kadsurenone could directly affect osteoclastogenesis. We firstly confirmed that no significant cytotoxicity of Kadsurenone on mouse BMMs under a certain concentration (Fig. 4A). However, the process of RANKL induced Trap positive osteoclasts differentiated by BMMs were significantly attenuated by Kadsurenone dose dependently (Fig. 4B-D). Meanwhile, acting ring formation were also restrained (Fig. 4E and F).

Kadsurenone inhibits RANKL induced OC marker genes expression by inhibiting the $N F-\kappa B$ pathway. To investigate potential mechanisms of the inhibitory function of Kadsurenone on BMMs differentiation. RT-PCR (Fig. 5A) and RT-qPCT (Fig. 5B) assay were performed. Results indicated that the expression of osteoclast marker genes Ctsk, Trap, and nuclear factor of activated T cells 1 (Nfatc1) were all inhibited by Kadsurenone. Luciferase assay indicated that the transcription factors $N F-\kappa B$ and Nfatcl activities were all attenuated (Fig. 5C). 
A

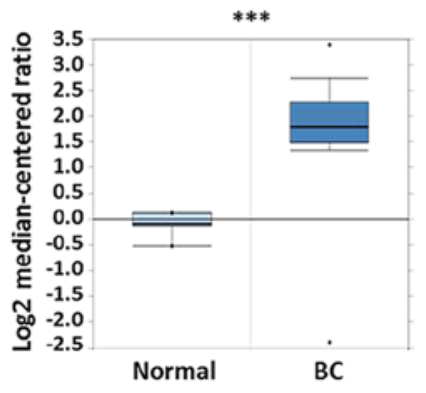

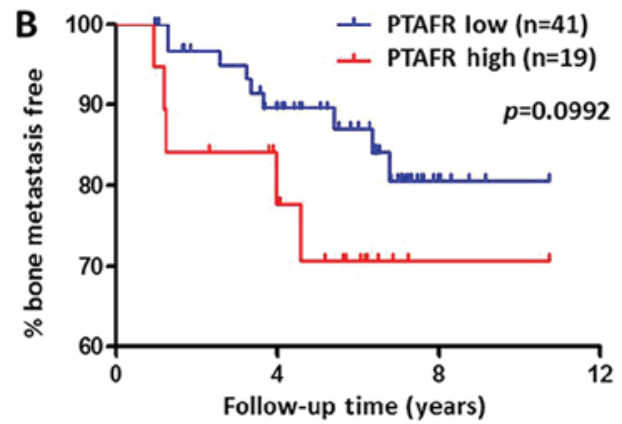

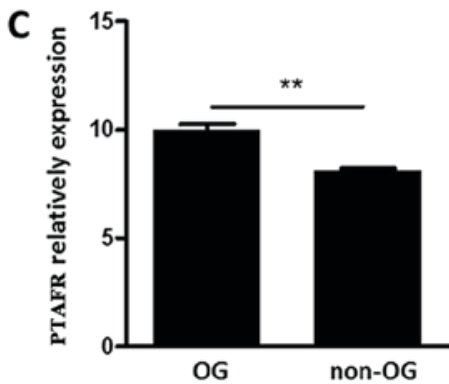

Figure 1. Bioinformatics analysis of PTAFR expression in BC tissues and OG cell lines. (A) Expression fold changes of PTAFR in patients with BS vs. normal breast tissues. The data were obtained from the Oncomine database. (B) Survival analysis using the PTAFR mRNA expression level for incidences of bone metastasis in Minn's dataset, P-values were calculated on the basis of a log-rank test. (C) Comparison of PTAFR mRNA relative expression in OG and non-OG cell lines following Rankl stimulation. Data were obtained from the GSE43811 dataset and are presented as the mean \pm standard error of the mean ( $\mathrm{n}=3$ ). $\mathrm{P}$-values were calculated using a Student's t-test. ${ }^{* *} \mathrm{P}<0.01$ and ${ }^{* * * *} \mathrm{P}<0.001$. OG, osteoclastogenic; PTAFR, platelet-activating factor receptor; $\mathrm{BC}$, breast cancer.

A<smiles>C=CCC1=CC2(OC)CC(c3ccc(OC)c(OC)c3)OC2=CC1=O</smiles>

B

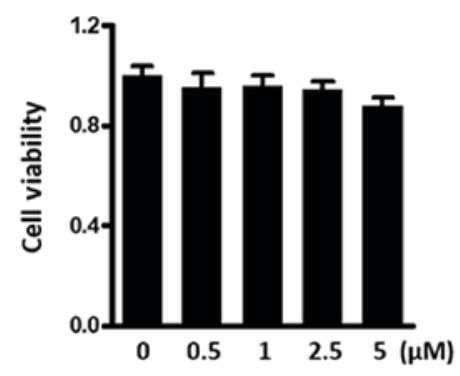

C

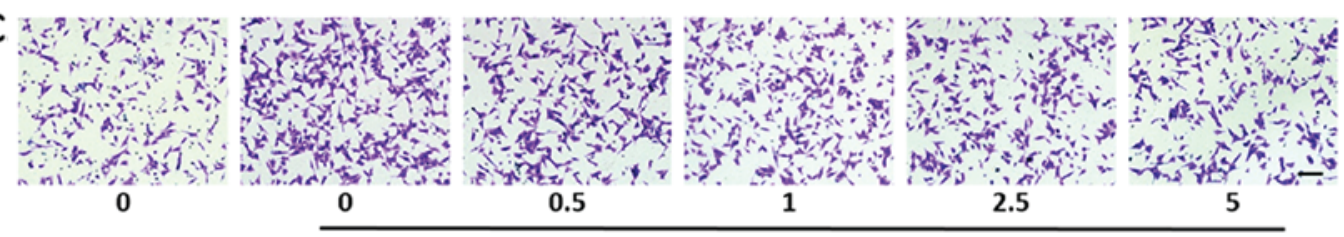

PAF (200 nM)

\section{D}

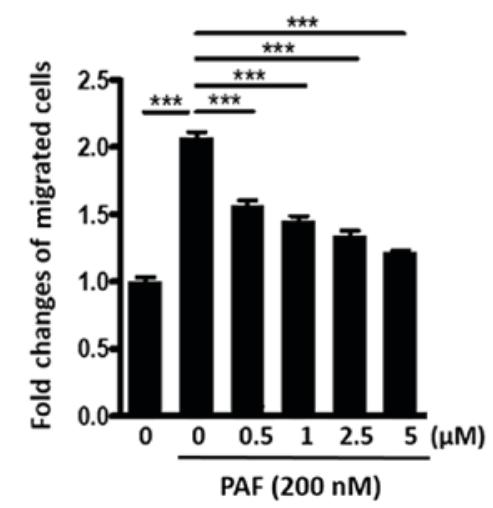

E

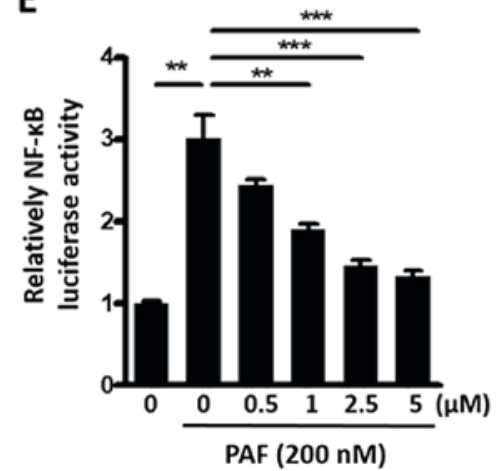

Figure 2. Kadsurenone inhibits PAF induced BC cell migration. (A) Chemical structure of Kadsurenone. (B) Effect of Kadsurenone on the viability of BC cell line MDA-MB-231. MDA-MB-231 cells were treated with the indicated concentrations of Kadsurenone. (C) Transwell assay of MDA-MB-231 cells induced by PAF (200 nM) with the presence or absence of the indicated concentrations of Kadsurenone. (D) Graphs represent the mean fold changes of migrated cells from three independent experiments. (E) Relative NF- $\mathrm{B}$ luciferase activity of MDA-MB-231 cells induced by PAF (200 nM) with the presence or absence of indicated concentrations of Kadsurenone. Data are presented as the mean \pm standard error of the mean $(\mathrm{n}=3)$. Scale bar, $100 \mu \mathrm{m}$. P-values were calculated using one-way analysis of variance followed by Tukey's post hoc test. ${ }^{* *} \mathrm{P}<0.01$ and ${ }^{* * *} \mathrm{P}<0.001$. PAF, platelet-activating factor; BC, breast cancer; NF, nuclear factor.

\section{Discussion}

Bone metastasis is a deleterious and debilitating aspect of $\mathrm{BC}$ patients. Up to $70 \%$ of $\mathrm{BC}$ patients who succumb to disease present with bone metastases on autopsy (27). Bone metastases lesions are primarily osteolytic since BC cells could regulate the bone-tumor microenvironment (28-30). Osteoclasts were over activated by BC cells while BC cells were reversely promoted by cytokines released from bone matrix degradation. Current treatment strategies for BC bone metastases mainly focused on breaking such 'vicious osteolytic cycle' (31-33). Bioinformatics analysis provided clues that the PAF/PTAFR 
A

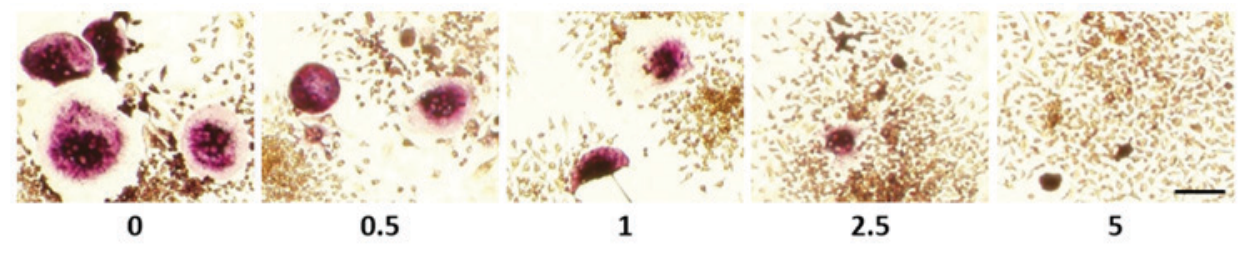

B

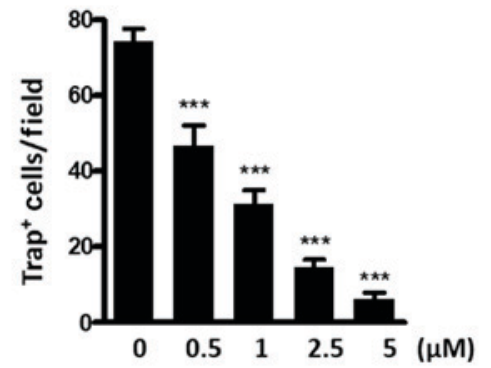

C

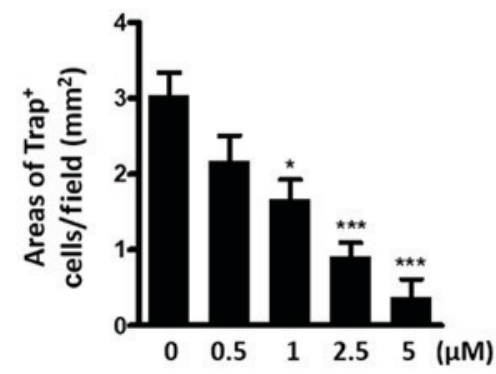

Figure 3. Kadsurenone inhibits breast cancer cells induced osteoclastogenesis. (A) Representative images of Trap ${ }^{+}$osteoclasts. MDA-MB-231 and RAW264.7 cells were co-cultured and treated with the indicated concentrations of Kadsurenone and stained on day 7. The (B) number and (C) area of Trap ${ }^{+}$osteoclasts per field are reported. Scale bar, $100 \mu \mathrm{m}$. Data are presented as the mean \pm standard error of the mean $(\mathrm{n}=3)$. P-values were calculated using one-way analysis of variance followed by Tukey's post hoc test. ${ }^{*} \mathrm{P}<0.05$ and ${ }^{* * *} \mathrm{P}<0.001$ vs. the control. Trap, tartrate-resistant acid phosphatase.

A

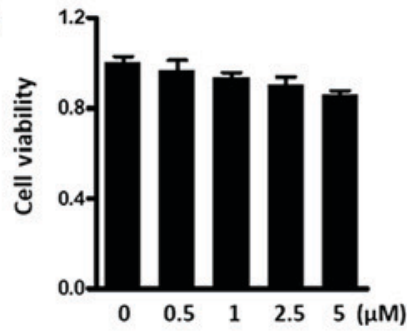

B

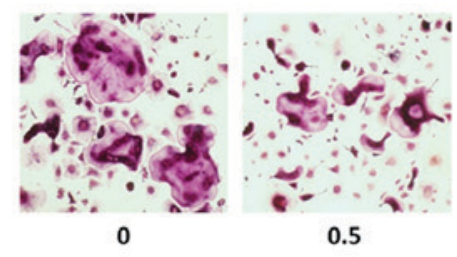

E
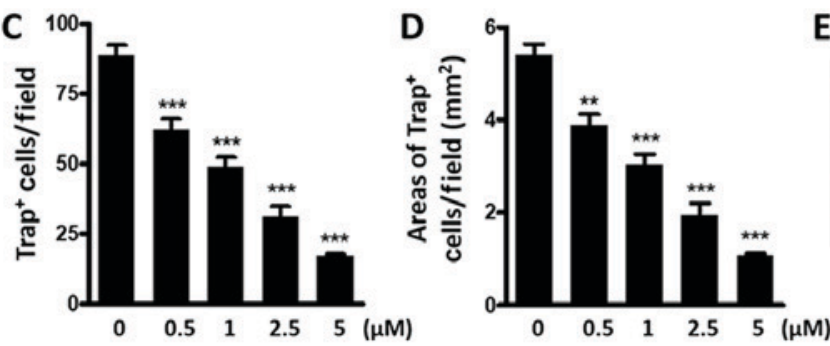

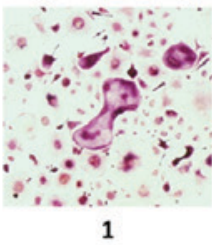

1

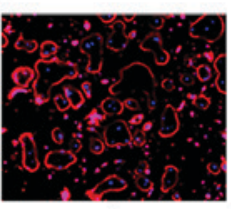

$\mathbf{R}$

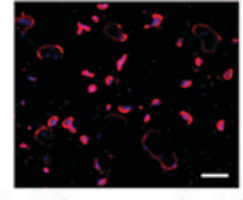

R+Kadsurenone $(1 \mu \mathrm{M})$

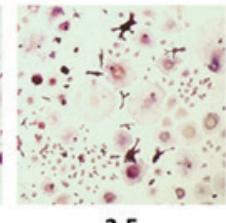

2.5

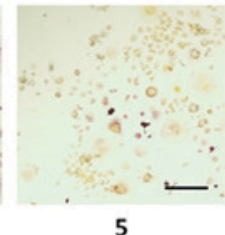

Figure 4. Kadsurenone directly inhibits RANKL induced osteoclastogenesis. (A) Effect of Kadsurenone on the viability of mouse BMMs. Mouse BMMs were isolated and treated with the indicated concentrations of Kadsurenone. (B) Representative images of Trap ${ }^{+}$osteoclasts. Mouse BMMs were isolated and induced for osteoclastogenesis with RANKL $(50 \mathrm{ng} / \mathrm{ml})$. Cells were treated with thye indicated concentrations of Kadsurenone and stained on day 7 . The (C) number and (D) area of Trap ${ }^{+}$osteoclasts per field are indicated (E) Representative images of actin ring staining. Mouse BMMs were isolated and induced for osteoclastogenesis with RANKL $(50 \mathrm{ng} / \mathrm{ml})$. Cells were treated with the indicated concentrations of Kadsurenone and stained on day 7. (F) The bar chart represents the mean number of actin rings for three independent experiments. Scale bar, $100 \mu \mathrm{m}$. Data are presented as the mean \pm standard error of the mean $(\mathrm{n}=3)$. P-values were calculated using one-way analysis of variance followed by Tukey's post hoc test. ${ }^{* *} \mathrm{P}<0.01$ and ${ }^{* * * *} \mathrm{P}<0.001$ vs. the control. BMMs, bone marrow monocytes; RANKL, receptor activator for NF- $\kappa \mathrm{B}$ ligand; Trap, tartrate-resistant acid phosphatase.

signaling pathway may play important roles in regulating $\mathrm{BC}$ bone metastasis and osteoclastogenesis. In the current study, we demonstrated that PAF could promote BC cell migration and induce BMMs differentiation. Besides, it has been reported that absence of PAFR protects mice from osteoporosis following ovariectomy, and PAF could enhance osteoclast differentiation directly. Kadsurenone could attenuate both processes, and could be considered as a potential therapeutic reagent for $\mathrm{BC}$ bone metastases.

PAF can be synthesized within variety of cells like platelets, macrophages, eosinophils, basophils and endothelial cells by de novo or remodeling pathways and cause different physiological reactions $(34,35)$. The expression of PAF and its receptor PTAFR in BC cell lines have also been demonstrated $(17,18)$. In the tumor microenvironment, PAF is secreted and accumulated by infiltrated inflammation cells and tumor cells per se, which forms an autocrine loop. PTAFR is a GPCR. PAF/PTAFR activation resulted complex cell responses including increase of cell motility, upregulation of IL-6 and matrix metalloproteinase (MMP) expression, and activation of $N F-\kappa B$ signaling (34). The increased migration ability is an important characteristic for cancer cells forming metastatic 
A

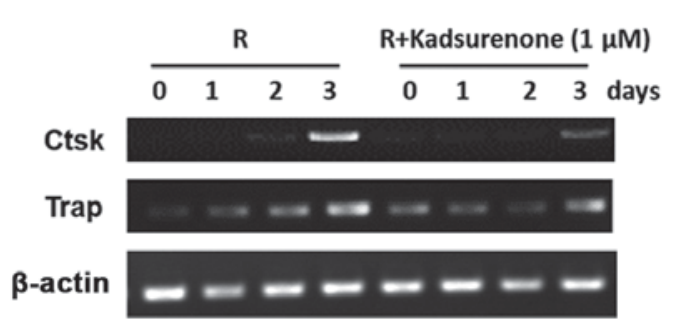

B

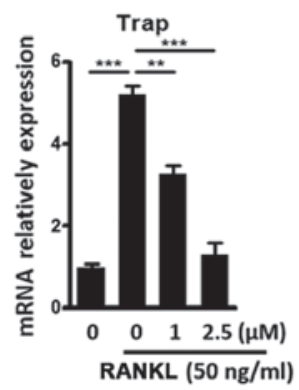

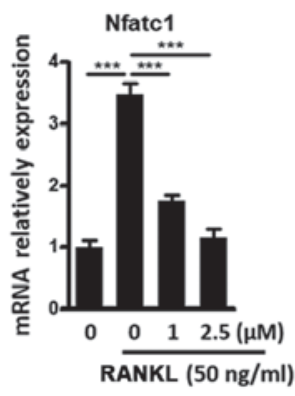

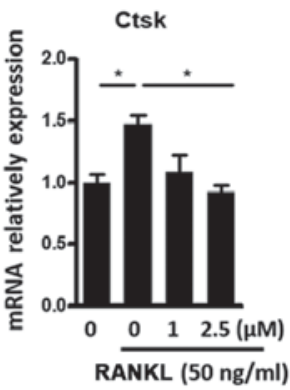

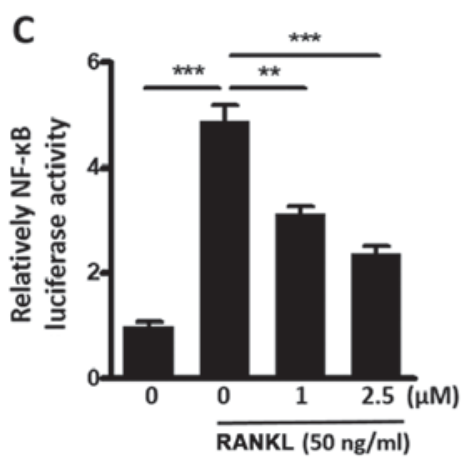

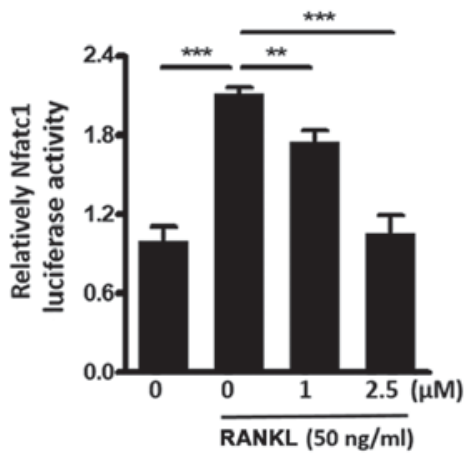

Figure. 5 Kadsurenone inhibits RANKL induce OC marker gene expression by inhibiting the NF- $\mathrm{kB}$ signaling pathway. (A) RT-qPCR analysis of the OC marker gene Ctsk and Trap expression. Mouse BMMs were isolated and induced for osteoclastogenesis with Rank 1 (50 ng/ml). Cells were treated with or without $1 \mu \mathrm{M}$ Kadsurenone. mRNAs were harvested on the indicated days. (B) RT-qPCR analysis of the OC marker genes Trap, Nfatc1 and Ctsk expression. Mouse BMMs were isolated and induced for osteoclastogenesis with RANKL $(50 \mathrm{ng} / \mathrm{ml})$. Cells were treated with the indicated concentrations of Kadsurenone. mRNAs were harvested on day 3. (C) Relative NF- $\mathrm{kB}$ (left) and Nfatc1 (right) luciferase activity of mouse BMMs induced by RANKL (50 ng/ml) with the presence or absence of the indicated concentrations of Kadsurenone. Data are presented as the mean \pm standard error of the mean $(\mathrm{n}=3)$. P-values were calculated using one-way analysis of variance followed by Tukey's post hoc test. ${ }^{*} \mathrm{P}<0.05,{ }^{* *} \mathrm{P}<0.01$ and ${ }^{* * * *} \mathrm{P}<0.001$ vs. the control. BMMs, bone marrow monocytess; RT-qPCR, reverse transcription-quantitative polymerase chain reaction; OC, osteoclast; Ctsk, cathepsin K; Nfatc1, nuclear factor of activated T cells 1; Trap, tartrate-resistant acid phosphatase; RANKL, receptor activator for NF-אB ligand; NF, nuclear factor.

lesions, including bone metastases (36). Both of published literatures and our results revealed increased cell migration ability of BC cells after PAF treatment. To avoid the harmful effects of PAF, mostly PAF inhibitors are used to abolish or attenuate the PAF/PTAFR signaling activation $(37,38)$. Comparing to synthetic PAF inhibitors, natural inhibitors are preferred due to the safety reason (34). In the current study, we used the natural herbal extraction Kadsurenone effectively abolished PAF induced BC migration, and little cytotoxicity manifested.

The great majority of $\mathrm{BC}$ produces osteolytic bone metastases $(9,39,40)$. This process is characterized by over activated osteoclastogenesis and subsequent bone destruction. $\mathrm{BC}$ cells could form a complex and multigenic programed 'vicious osteolytic cycle' to remold the bone microenvironment and promote cancer progression after, or even before, bone colonization $(28,36,41)$. Cytokines secreted by BC cells like IL-6, parathyroid hormone like hormone (PTHRP) and TNF $\alpha$ could stimulate osteoblasts and upregulate the RANKL/osteoprotegerin (OPG) ratio, which further stimulates the development of osteoclasts from myeloid precursors. At the same time, other cytokines such as IL-11 and osteopontin (OPN) could directly promote ostoclastogenesis. Activated osteoclasts degrade the bone matrix, and release transforming growth factor $\beta$ (TGF $\beta$ ), bone morphogenetic protein (BMPs) and insulin-like growth factor (IGFs), which are mainly stored in bone matrix, reversely stimulate $\mathrm{BC}$ progression.
Comparing to the 'vicious osteolytic cycle', PAF could promote BMMs differentiate into osteoclasts by two parallel manners. On one hand, PAF could stimulate BC cells upregulate downstream signaling such as IL-6, IL-11, MMPs and NF- $\kappa B$, which further activate osteoclastogenesis (34). On the other hand, PAF could also directly activate BMMs differentiate into osteoclasts $(20,21)$. In the current study, we demonstrated that Kadsurenone could inhibit both the BC induced or PAF directly stimulated osteoclastogenesis. Expression of osteoclast differentiation markers are all downregulated after Kadsurenone treatment. It is known that NFATc1 is the master transcription factor for osteoclast differentiation. NF- $\kappa \mathrm{B}$ regulates RANKL induced osteoclast differentiation mainly through promoting NFATc1 transcription activity. NF- $\kappa \mathrm{B}$ is a critical signal for OC differentiation downstream of RANKL, Mice lacking the subunit p50 and $\mathrm{p} 52$ of NF- $\kappa \mathrm{B}$ signal pathway have been shown to be osteopetrotic p50-/- or p52-/- precursors fail to form OCs. The results in our study indicated that PAF might partially inhibited NF- $\mathrm{KB}$ activation and osteoclast differentiation via blocking NFATc1 transcription activity.

In conclusion, Kadsurenone maybe an effectively strategy to attenuate $\mathrm{BC}$ formed osteolytic bone metastases by blocking the PAF/PTAFR signaling. Nonetheless, many questions pertaining to be answered. Further studies are requested to reveal detailed mechanisms of Kadsurenone function and in vivo studies are needed. 


\section{Acknowledgements}

Not applicable.

\section{Funding}

No funding was received.

\section{Availability of data and materials}

The datasets used and/or analyzed during the current study are available from the corresponding author on reasonable request.

\section{Authors' contributions}

HT performed the experiments and drafted the manuscript. LY, LS and ZC performed the data analyses and wrote the manuscript. JY, WD, TL, ZM, XW, QM and WZ performed the experiments. ZJ and $\mathrm{WH}$ helped perform the data analysis. LZ contributed to the conception of the study. XJ contributed to the conception of the study and revised the manuscript critically for important intellectual content.

\section{Ethics approval and consent to participate}

All experimental protocols were approved by the Review Committee for the Use of Human or Animal Subjects of East China Normal University and Chang Zheng Hospital.

\section{Consent for publication}

Not applicable.

\section{Competing interests}

The authors confirm that they have no competing interests.

\section{References}

1. Siegel RL, Miller KD and Jemal A: Cancer Statistics, 2017. CA Cancer J Clin 67: 7-30, 2017.

2. Chen W, Zheng R, Baade PD, Zhang S, Zeng H, Bray F, Jemal A, Yu XQ and He J: Cancer statistics in China, 2015. CA Cancer J Clin 66: 115-132, 2016.

3. Coleman RE: Metastatic bone disease: Clinical features, pathophysiology and treatment strategies. Cancer Treat Rev 27: 165-176, 2001.

4. Selvaggi G and Scagliotti GV: Management of bone metastases in cancer: A review. Crit Rev Oncol Hematol 56: 365-378, 2005.

5. Sutcliffe P, Connock M, Shyangdan D, Court R, Kandala NB and Clarke A: A systematic review of evidence on malignant spinal metastases: natural history and technologies for identifying patients at high risk of vertebral fracture and spinal cord compression. Health Technol Assess 17: 1-274, 2013.

6. Kelly ML, Kshettry VR, Rosenbaum BP, Seicean A and Weil RJ: Effect of a randomized controlled trial on the surgical treatment of spinal metastasis, 2000 through 2010: A population-based cohort study. Cancer 120: 901-908, 2014.

7. Nguyen DX, Bos PD and Massagué J: Metastasis: From dissemination to organ-specific colonization. Nat Rev Cancer 9: 274-284, 2009.

8. Sutherland A, Forsyth A, Cong Y, Grant L, Juan TH, Lee JK, Klimowicz A, Petrillo SK, Hu J, Chan A, et al: The role of prolactin in bone metastasis and breast cancer cell-mediated osteoclast differentiation. J Natl Cancer Inst 108, 2015.
9. von Moos R, Sternberg C, Body JJ and Bokemeyer C: Reducing the burden of bone metastases: Current concepts and treatment options. Support Care Cancer 21: 1773-1783, 2013.

10. Li BT, Wong MH and Pavlakis N: Treatment and prevention of bone metastases from breast cancer: A comprehensive review of evidence for clinical practice. J Clin Med 3: 1-24, 2014.

11. Damiani E and Ullrich SE: Understanding the connection between platelet-activating factor, a UV-induced lipid mediator of inflammation, immune suppression and skin cancer. Prog Lipid Res 63: 14-27, 2016.

12. Pałgan $\mathrm{K}$ and Bartuzi Z: Platelet activating factor in allergies. Int J Immunopathol Pharmacol 28: 584-589, 2015.

13. Liu Y, Shields LBE, Gao Z, Wang Y, Zhang YP, Chu T, Zhu Q, Shields CB and Cai J: Current understanding of platelet-activating factor signaling in central nervous system diseases. Mol Neurobiol 54: 5563-5572, 2017.

14. McHowat J, Gullickson G, Hoover RG, Sharma J, Turk J and Kornbluth J: Platelet-activating factor and metastasis: Calcium-independent phospholipase A $2 \beta$ deficiency protects against breast cancer metastasis to the lung. Am J Physiol Cell Physiol 300: C825-C832, 2011.

15. Wu JT and Kral JG: The NF-kappaB/IkappaB signaling system: A molecular target in breast cancer therapy. J Surg Res 123: 158-169, 2005.

16. Wang X, Jung YS, Jun S, Lee S, Wang W, Schneider A, Sun Oh Y, Lin SH, Park BJ, Chen J, et al: PAF-Wnt signaling-induced cell plasticity is required for maintenance of breast cancer cell stemness. Nat Commun 7: 10633, 2016.

17. Bussolati B, Biancone L, Cassoni P, Russo S, Rola-Pleszczynski M, Montrucchio G and Camussi G: PAF produced by human breast cancer cells promotes migration and proliferation of tumor cells and neo-angiogenesis. Am J Pathol 157: 1713-1725, 2000.

18. Anandi VL, Ashiq KA, Nitheesh K and Lahiri M: Platelet-activating factor promotes motility in breast cancer cells and disrupts non-transformed breast acinar structures. Oncol Rep 35: 179-188, 2016.

19. Langdahl B, Ferrari S and Dempster DW: Bone modeling and remodeling: Potential as therapeutic targets for the treatment of osteoporosis. Ther Adv Musculoskelet Dis 8: 225-235, 2016.

20. Zheng ZG, Wood DA, Sims SM and Dixon SJ: Platelet-activating factor stimulates resorption by rabbit osteoclasts in vitro. Am J Physiol 264: E74-E81, 1993.

21. Wood DA, Hapak LK, Sims SM and Dixon SJ: Direct effects of platelet-activating factor on isolated rat osteoclasts. Rapid elevation of intracellular free calcium and transient retraction of pseudopods. J Biol Chem 266: 15369-15376, 1991.

22. Kim H, Kim BJ, Ahn SH, Lee SH and Koh JM: Higher plasma platelet-activating factor levels are associated with increased risk of vertebral fracture and lower bone mineral density in postmenopausal women. J Bone Miner Metab 33: 701-707, 2015.

23. Huang SP, Lin LC, Wu YT and Tsai TH: Pharmacokinetics of kadsurenone and its interaction with cyclosporin $\mathrm{A}$ in rats using a combined HPLC and microdialysis system. J Chromatogr B Analyt Technol Biomed Life Sci 877: 247-252, 2009.

24. Zhang N, Li R, Yu H, Shi D, Dong N, Zhang S and Wang H: Development of an LC-MS/MS method for quantification of kadsurenone in rat plasma and its application to a pharmacokinetic study. Biomed Chromatogr 27: 1754-1758, 2013.

25. Minn AJ, Gupta GP, Siegel PM, Bos PD, Shu W, Giri DD, Viale A, Olshen AB, Gerald WL and Massagué J: Genes that mediate breast cancer metastasis to lung. Nature 436: 518-524, 2005.

26. Hikiji H, Ishii S, Shindou H, Takato T and Shimizu T: Absence of platelet-activating factor receptor protects mice from osteoporosis following ovariectomy. J Clin Invest 114: 85-93, 2004.

27. Johnson RW, Finger EC, Olcina MM, Vilalta M, Aguilera T, Miao Y, Merkel AR, Johnson JR, Sterling JA, Wu JY and Giaccia AJ: Induction of LIFR confers a dormancy phenotype in breast cancer cells disseminated to the bone marrow. Nat Cell Biol 18: 1078-1089, 2016.

28. Kang Y, Siegel PM, Shu W, Drobnjak M, Kakonen SM, Cordón-Cardo C, Guise TA and Massagué J: A multigenic program mediating breast cancer metastasis to bone. Cancer Cell 3: 537-549, 2003.

29. Roodman GD: Mechanisms of bone metastasis. N Engl J Med 350: 1655-1664, 2004. 
30. Macedo F, Ladeira K, Pinho F, Saraiva N, Bonito N, Pinto L and Goncalves F: Bone metastases: An overview. Oncol Rev 11: 321, 2017.

31. Trémollieres FA, Ceausu I, Depypere H, Lambrinoudaki I, Mueck A, Pérez-López FR, van der Schouw YT, Senturk LM, Simoncini T, Stevenson JC, et al: Osteoporosis management in patients with breast cancer: EMAS position statement. Maturitas 95: 65-71, 2017.

32. Van Acker HH, Anguille S, Willemen Y, Smits EL and Van Tendeloo VF: Bisphosphonates for cancer treatment: Mechanisms of action and lessons from clinical trials. Pharmacol Ther 158: 24-40, 2016.

33. Santini D, Stumbo L, Spoto C, D'Onofrio L, Pantano F, Iuliani M, Fioramonti M, Zoccoli A, Ribelli G, Virzì V, et al: Bisphosphonates as anticancer agents in early breast cancer: preclinical and clinical evidence. Breast Cancer Res 17: 121, 2015.

34. Singh P, Singh IN, Mondal SC, Singh L and Garg VK: Platelet-activating factor (PAF)-antagonists of natural origin. Fitoterapia 84: 180-201, 2013.

35. Tsoupras AB, Fragopoulou E, Nomikos T, Iatrou C, Antonopoulou S and Demopoulos CA: Characterization of the de novo biosynthetic enzyme of platelet activating factor, DDT-insensitive cholinephosphotransferase, of human mesangial cells. Mediators Inflamm 2007: 27683, 2007.
36. Weilbaecher KN, Guise TA and McCauley LK: Cancer to bone: A fatal attraction. Nat Rev Cancer 11: 411-425, 2011

37. Kasperska-Zajac A, Brzoza Z and Rogala B: Platelet-activating factor (PAF): A review of its role in asthma and clinical efficacy of PAF antagonists in the disease therapy. Recent Pat Inflamm Allergy Drug Discov 2: 72-76, 2008.

38. Imrie CW and McKay CJ: The possible role of platelet-activating factor antagonist therapy in the management of severe acute pancreatitis. Baillieres Best Pract Res Clin Gastroenterol 13: 357-364, 1999.

39. Waning DL and Guise TA: Molecular mechanisms of bone metastasis and associated muscle weakness. Clin Cancer Res 20: 3071-3077, 2014

40. Cox TR, Gartland A and Erler JT: Lysyl oxidase, a targetable secreted molecule involved in cancer metastasis. Cancer Res 76: 188-192, 2016.

41. Cox TR, Rumney RM, Schoof EM, Perryman L, Høye AM, Agrawal A, Bird D, Latif NA, Forrest H, Evans HR, et al: The hypoxic cancer secretome induces pre-metastatic bone lesions through lysyl oxidase. Nature 522: 106-110, 2015.

This work is licensed under a Creative Commons Attribution-NonCommercial-NoDerivatives 4.0 International (CC BY-NC-ND 4.0) License. 